\title{
EDITOR'S REPORT 2008-2009
}

Editorship of the Proceedings of NSIS changed hands in October, 2008. On behalf of the Institute, I thank and congratulate Dr. James (Jim) E. Stewart for the excellent job that he did as Editor since 2002, for his numerous written contributions to the journal, and for the assistance offered to me as incoming Editor over the past year.

The Proceedings of the Nova Scotian Institute of Science, Volume 44 Parts 1 and 2, were published in August 2007 and August 2008, respectively. Vol. 44(1) had five contributed papers, including a bibliographical overview of Donald Hebb, a distinguished psychologist from Nova Scotia; one prize winning student science paper; and obituaries of two prominent aquatic scientists from Halifax. Volume 44(2) had six contributed papers, including three on environmental conditions in Sydney harbour, NS, and two prize-winning student science papers. Both issues included reports of the Institute. Volume 44 was edited by Dr. Stewart.

Preparation of Volume 45, Part 1, is on-going, with two contributed papers submitted, two more in preparation, several more being solicited, and three prize winning science papers in hand. Publication of Volume 45(1) is expected to be late Summer 2009. There are a number of proposed submissions, both for specific papers and special issues over the next 3 years, and authors and special editors will be sought.

The Proceedings of the NSIS have a distinguished history and a bright future in a region noted for its scientific innovation and output. The journal is a major outlet for papers on the natural sciences of the Atlantic Provinces. It is my hope that the journal's profile will be enhanced in coming years, given the importance of science to the economic and environmental well being of our region. Indeed this has already begun through the Institute's efforts to place the Journal's contents onto its website.

Every member of NSIS and every reader should consider submitting articles on new research results, reviews, viewpoints and book reviews, to help continue the tradition of the Proceedings being a timely, salient and visible outlet for regional science in all of its dimensions. As well, suggestions from NSIS members and non-members as to the future role and future content of the Proceedings are always welcome.

Respectfully submitted to the AGM

May $4^{\text {th }}, 2009$

Peter G. Wells

Editor, NSIS 